'Tacit knowledge': the variety of meanings in empirical research

Stephen Gourlay

Kingston Business School

Kingston upon Thames

KT2 7LB, UK.

sngourlay@kingston.ac.uk 


\title{
'Tacit knowledge': the variety of meanings in empirical research
}

\begin{abstract}
Discussion of tacit knowledge shows much ambiguity over key aspects of the concept. Rather than turning to further theory, this paper examines how the phrase has been applied in empirical research. Eight different uses of the term are identified, six concerning individual level and two collective level notions. Focusing on individual level notions it is argued that some of these uses involve explicitly known knowledge, or stretch the meaning of the phrase beyond credulity. It is suggested that the phrase be used where it can clearly be inferred that actors' behaviour depended on knowledge of which they were unaware. Such knowledge can arise prior to or in a practice. Some implications for managing tacit knowledge are also considered.
\end{abstract}

\section{Introduction}

There is widespread agreement that tacit knowledge is an important phenomenon. Nonaka and his colleagues regard it as the root of all organizational knowledge (Nonaka \& Takeuchi 1995). Collins has shown that it is critical even in activities like scientific experiments (Collins 2001a, b) and he along with many others regard tacit knowledge as fundamental to all human knowing and knowledge. Beyond such general agreement however we find important differences of opinion over many key aspects of tacit knowledge, such as the level at which it is manifested, how it is acquired, what its function is, and whether or not it can be made explicit.

There are ambiguities concerning the level at which we might expect to find tacit knowledge, or at least, its effects. Most people treat it as personal, private knowledge, thus appropriately treated only at the individual level (Johannessen et al 2001: 8; Ambrosini \& Bowman 2001: 812-3; Boiral 2002: 296; Fleck 1996, quoted in Johannessen et al 2001: 4). Others refer to collective tacit knowledge as something different (Colis 1996 149-50; Spender 1996: 62, 64; Leonard \& Sensiper 1998: 121-2), and while Colis equates this with organizational capability, others refer to routines, procedures and the like as organizational tacit knowledge (Colis 1996; Johannessen et al 2001: 8, Nelson \& Winter, 1982; Leonard \& Sensiper 1998: 113-4, 121-2; Stenmark 2000-01). If we regard humans as essentially socialized beings, then this distinction may be a false or misleading one, however.

There is general agreement that tacit knowledge is acquired through an individual's direct experience of whatever their tacit knowledge concerns ( Marchant \& Robinson 1999:3; Patel et. al. 1999: 76; Herbig et al 2001: 688-90). At work, for example, on the job training and informal learning are important means of acquisition (Wagner et. al. 1999: 157). On the other hand, some argue that we are biologically predisposed towards certain aspects or kinds of tacit knowledge, suggesting experience is not necessarily a factor (Torff 1999: 198-9; Patel et. al. 1999: 78). While these differences could be reconciled within some models of human development (Richardson 1998) no attempt has been made to do so for tacit knowledge acquisition.

In keeping with the emphasis on the individual, Horvath et. al. (1999) say tacit knowledge is acquired with little help from others. However, they appear to be in a minority as there is widespread agreement that personal contact with and observation of others are critical factors in its acquisition (Collins 2001a: 72-3; Collins 2001b: 107; Leonard \& Sensiper 1998: 121, 124). While little is usually said about what 'personal contact' means detailed accounts (Cook and Brown 1999: 391 ff.; see also Collins 2001a 74-79) suggest a complex iterative process of 
acting on the materials being transformed, working with others more expert in the field, receiving their judgement on transformation efforts, attempting to meet their standards and see what they see, identifying critical factors, and so on.

Discussion of the role or function of tacit knowledge also reveals important ambiguities. On the one hand tacit knowledge is said to be essential for competent performance in concrete situations ("practical intelligence" - Wagner et. al. 1999; Wagner \& Sternberg 1986: 51), to enable individuals to deal with new situations, and to fill in the gaps in formal training (Horvath et al 1999; Marchand \& Robinson 1999; Argyris 1999; Collins 2001a, b). These remarks suggest that tacit knowledge facilitates adaptation to new situations particularly since it enables people to act quickly without having to deliberate (Josefson 1988: 26; Herbig et al 2001: 688, 690; Wagner et al 1999). On the other hand, in so far as tacit knowledge stems from biological givens (Torff 1999) then implicitly it could hinder change since such knowledge is relatively fixed. Argyris in particular notes the contradictory duality of tacit knowledge suggesting it is both the basis of successful management, and of defensive routines (1999: 123). Herbig et. al. (2001: 688) note that tacit knowledge sometimes contains naive and wrong theories raising questions about its efficacy.

Similar contradictions can be seen at the organizational level. Some view tacit knowledge as the source of all knowledge, and particularly of innovative ideas, in organizations (Nonaka 1991; Ichijo et. al. 1998: 180; Nonaka \& Takeuchi 1995) and for others it is the source of sustained competitive advantage (Ambrosini \& Bowman 2001; Baumard 1999; Scharmer 2000; Choo 1998; see Johannessen et. al. 2001 for a review). Others, however, note that it in so far as it is manifested in traditions, tacit knowledge is a conservative rather than an innovative force (Johannessen et al 2001: 11; Fleck 1996, cited in Johannesen et. al. 2001). Indeed, it may be because it is conservative and tradition-bound that tacit knowledge can be a source of sustainable competitive advantage precisely because traditions cannot easily be copied.

One issue that has aroused much interest, particularly following Nonaka and Takeuchi's (1995) thesis about knowledge creation, has been whether tacit knowledge can be converted into explicit knowledge. Again, we find widely and strongly differing opinions. Some aver that tacit knowledge cannot be expressed in written or verbal form because it is by definition non-verbal, inarticulable, unconscious, or ineffable (Patel et. al. 1999: 76; Collins 2001a: 72; Collins 2001b: 108; Ambrosini \& Bowman 2001: 812-3; Herbig \& Büssing 2003: 167; Tsoukas 2003). On the other hand, others simply say is it rarely expressed, or difficult to express or simply assume that it can be made explicit. Difficulties include the fact that it is by definition personal and context based, that the holder might stand to lose by making it explicit, and that explication requires a supportive environment involving trust and appropriate organizational structures (Torff 1999: 195; Fleck 1996 quoted in Johannessen et al 2001: 4; Boiral 2002: 296; Spender 1996: 58; Nonaka \& Takeuchi 1995, Wagner \& Sternberg 1986; Wagner \& Sternberg 1991). Nonaka and Takeuchi's model assumes a steady traffic between tacit and explicit knowledge while Patel et. al. (1999: 88) independently write of conceptual change arising from a tacit-explicit-tacit cycle.

In the light of these difficulties with the concept it is not surprising to find claims that the notion is under-specified, that it carries too many meanings, or that we only have a nascent understanding of tacit knowledge, and that it resists operationalization (Ambrosini \& Bowman 2001: 811; Leonard \& Sensiper 1998: 127; Spender 1996: 58). Tsoukas (2003) might disagree in so far as he argues that we have misunderstood Polanyi, who provided grounds for viewing tacit knowledge as "ineffable" (see Gourlay 2004 for an alternative interpretation of Polanyi's ideas). If it is claimed that tacit knowledge cannot be examined empirically because it is unconscious (Easterby-Smith and Lyles 2003: 8) or that it ineffable, this lends support to Donaldson's charge of mystification (Donaldson 2001). Wagner and Sternberg would 
presumably dispute many of these ideas since have operationalized a measure of managers' tacit knowledge.

\section{Towards greater clarity}

Two recent theoretical papers (Tsoukas 2003; Gourlay 2004) may have clarified the air in so far as they suggest that Polanyi's ideas may not be particularly relevant for understanding tacit knowledge in organizations. It is perhaps significant that neither Collins, nor Wagner and Sternberg - authors who have carried out much empirical research into tacit knowledge drew much if anything from Polanyi. Collins cited Wittgenstein as of greater significance in his work (Collins 1974: 184), and Wagner and Sternberg simply regard tacit knowledge as knowledge that is hidden or tacit in some sense (Wagner \& Sternberg 1985: 438-9). It is curious that the work of these authors has received little attention in knowledge management literature, which has also largely ignored the extensive research into unconscious cognitive processes, such as implicit learning (Stadler \& Frensch 1998).

Although there are further potentially useful sources of theory and empirical research it is not the purpose of this paper to review them. The focus here is on examining empirical studies that have called the phenomena under investigation 'tacit knowledge' or that have given explicit empirical examples of tacit knowledge. In general, theory develops both through semantic clarification, and by clarifying the nature of the objects that theory has apparently drawn our attention to. Indeed, we might find that since current tacit knowledge theory is weak or ambiguous empirical work has actually been more consistent (if only tacitly!), and a review would furnish sound means to contribute to the development of theory.

The volume of published articles on tacit knowledge precluded anything like the systematic review that would be desirable. A more traditional approach was taken working from literature to hand and following up further references. Even with this limitation it soon became apparent that further reading was yielding no new use categories. Three main constraints were observed. First, speculative and general discussion of tacit knowledge was bypassed to focus on identifying things that had been called 'tacit knowledge'. Second, the search was limited to literature relevant to the study of human activities in organizations. Third, further discussion of collective and/or organizational tacit knowledge was excluded. Such uses were derivative of the original emphasis on individual knowledge, and would in any case require attention to the issue of relations between different levels which would overcomplicate an already complicated topic. This area of use of 'tacit knowledge' thus remains to be examined.

Finally, it is important to note that what follows is NOT a typology of tacit knowledge. So long as there is no substantive agreement on manifestations or indicators of 'tacit knowledge' it is premature to talk of tacit knowledge types. The evidence considered here concerns ways in which the concept has been applied to empirical data. By studying this we can determine whether or not the notion has been applied consistently, and to what phenomena it has been applied to. This can then be used to further discussion of theoretical and practical aspects of tacit knowledge.

\section{'Tacit knowledge' in use - the evidence}

From this preliminary study it is evident that the phrase 'tacit knowledge' is used in six different ways. For convenience they will be described under four headings: knowledge where knowers are unaware; knowledge which was previously explicitly known; innate knowledge; and knowledge that some actors can tell, but others cannot because they are unaware of it. 
Examples of each of these use types will be described in the rest of this section.

\section{'Tacit knowledge' - the classic form}

In general these accounts concern people observed doing something of which they cannot give an account; or, their claim to be able to do something is verified by observation of the effects of their actions (see Table 1). Whether such tacit knowledge is claimed by actors, or inferred by observers, it is all related to action in particular contexts, and seems to have been acquired by such actions.

\section{Table 1: 'Knowledge' tacit to knowers}

\begin{tabular}{|l|l|}
\hline \multicolumn{1}{|c|}{ example } & \multicolumn{1}{|c|}{ source } \\
\hline $\begin{array}{l}\text { legal expertise - determining critical case factors; } \\
\text { identifying precedents; developing analogies; building } \\
\text { an argument }\end{array}$ & Marchant \& Robinson 1999 \\
\hline $\begin{array}{l}\text { knowing how to handle face to face selling; how to } \\
\text { maximise high probability sales situations; saleman's } \\
\text { rules of thumb }\end{array}$ & Wagner et. al. 1999 \\
\hline $\begin{array}{l}\text { setting up a scientific experiment - e.g. the care taken in } \\
\text { clamping the apparatus; in preparing experimental } \\
\text { materials (polishing a metal suspension thread; greasing } \\
\text { a silk suspension thread) }\end{array}$ & Collins 2001a \\
\hline $\begin{array}{l}\text { riding a bicycle; dancing } \\
\text { applying social rules; following conventions }\end{array}$ & $\begin{array}{l}\text { Collins 2001b; Cook and Brown } \\
1999\end{array}$ \\
\hline speaking acceptable phrases & Collins 2001b; Janik 1988 \\
\hline “knowledge ... manifested in traditions" & Collins 2001a \\
\hline nurses intuitions about patients' conditions & Collins 2001b; 1974 \\
\hline $\begin{array}{l}\text { managing oneself (knowledge about the importance of } \\
\text { tasks), and managing others (how to assign tasks) }\end{array}$ & Leonard \& Sensiper 1998 \\
\hline deciding which journal to submit an article to & Wagner \& Sternberg 1986 \\
\hline drawing inferences from various news stories & Bagner \& Sternberg 1986 \\
\hline doctors' rules of thumb for psychosocial problems & André et. al. 2002 \\
\hline making, and playing, musical instruments & Cook and Brown 1999 \\
\hline baker's ability to make tasty bread & Nonaka \& Takeuchi 1995 \\
\hline
\end{tabular}

In most of these examples the claim of tacit knowledge is implicitly validated by the fact that the actors have accomplished something. Collins' studies are amongst the most thorough investigations of tacit knowledge. Two of his studies (the development of a special kind of laser in the 1970s, and of the measurement of quality of sapphires in the 1990s) exemplify situations were one group of people are able to do something, but, despite their best efforts, are unable to explain it fully to others. The sapphire case (Collins 2001a) is particularly well documented in this respect.

While the theory behind the measurement of sapphire quality had been known for some time prior to the early 1990s, no one had succeeded in validating it. A Russian group was the first to do so, but when Western scientists were unable to repeat the experiments, the Russian success was discounted. It was not until a Russian team visited the UK, and demonstrated what they had done, were they believed. But then it became clear first that the experiment required a good deal of expertise to get it to work. More interesting, the Russians discovered that they did not fully understand how their set-up worked. It was only after much work with 
the apparatus did the two teams begin to realise the significance of certain materials, (specifically, a suspension thread) and of how they were prepared. In discussing this case, Collins refers to several 'types' of tacit knowledge - "mismatched salience" (people looking at the wrong thing); "ostensive knowledge" (knowledge that's easier to convey by pointing than talking), and "unrecognized knowledge", such as the importance of the suspension materials.

The studies by Marchant and Robinson (1999), Wagner et. al. (1999), and Wagner \& Sternberg (1986) contain less detail than Collins' reports, but the situations they described seem not too dissimilar. The same would seem to apply to Baumard's study (1999: 139-154) of a journalist's ability to make valuable inferences from apparently unpromising materials in ways he could not articulate. It is evident that many of these fall into Collins' 'motor-skills' category (Collins 2001b: 109) in that they involve people's ability to move and coordinate their bodies. While the mind-body distinction is in many respects unnecessary and misleading, nevertheless the notion of motor-skills calls up an image of mental skills. These seem to be at work in the ability to work with text and language, the application of social rules, and so on. Perceptual skills (implicit in for example assessing one's target in a sales situation, or one's adversary in court) might also be at work here. Nonaka and Takeuchi (1995: 60) talked about "mental models", a notion that is implicit in some of these examples, such as knowing social conventions.

In the following examples it is still the case that the knower claims to be unable to articulate their knowledge, but here there is typically some doubt about the connection between the action and the tacit knowledge, and instead a focus on knowers' 'feeling'. Johannessen et. al. (2002: 9-10) reported the case of a shipyard team whose idea for changes was difficult to explain "verbally to the engineers ... and the technical manager. ... because [it] was based on personal experience, intuition and a grasp of the situation as such, i.e. tacit knowledge." Nuclear weapon designers made decisions about what might or might not work in their computer programs on the basis of 'feel' and 'judgement' (MacKenzie \& Spinardi 1996: 26061) either because things could not be measured (internal workings of an exploding bomb) or because testing had been suspended. Similarly, Leonard \& Sensiper (1998: 125) reported a lime kiln operator left an interview "exclaiming simply "something is wrong; she [the kiln] doesn't sound right." Later pressed to explain, he could not — or would not - explicate further what sound he heard ... "It's nothing scientific," he said ... "Nothing an engineer would believe. I just know."' Whether or not something was wrong, and the operator put it right, we are not told. Willman et. al. (2001) reported that financial traders' tacit knowledge generated in trading resulted in experientially grounded 'feelings' about the market that they could not articulate. Examples of nurses feeling something about a patient might also fall into this group (Herbig et. al. 2001: 688), these have apparently been validated sometimes by subsequent events. Josefson recounts how a nurse felt something was wrong with a post-operative patient, but the doctor declared the vital signs gave no cause for alarm; the patient later died of complications (Josefson 1988: 26-7).

Some intriguing evidence discussed by Ichijo et. al. (1998) also seems to focus on feeling, although there is an implied connection between these and specific outcomes. Ichijo et. al. 1998 (171-203) studied a company operating in an industrial market where competitive advantage accrued through meeting emerging customer needs. Explicit market research seems not to have been carried out, and customers seldom made specific requests. Instead, we are told, they expressed their needs tacitly in conversations with the manufacturer. As a manager explained:

" '... What is important for us is to keep in close contact with various customers and read into their thoughts and desires. We come to understand what they want to do while talking with them about various things." "(Ichijo et. al. 1998: 184-5). 
When someone from this company "grasps this inarticulated 'tacit idea', there is in-depth communication and mutual understanding between the customer and the company which will lead to the development of an innovative product. ...". According to another manager, "we come to see what our customers expect towards the future while we listen, consider various problems and forecast upcoming changes with them'..." (Ichijo et. al. 1998: 181).

Similar processes operated within the company, between senior managers. The company is a confederation of independent organizations (Ichijo et. al. 1998: 171-80). Annual plans for each member organization were only summarized on one A4 sheet of paper because what "people consider the most important thing in these plans is ... 'communication based on tacit knowledge':

“ 'Our business plans come from our heart. Even if the plan's presentation is clumsy, it is highly evaluated if it contains a certain belief. While I am reading it, such a belief is emerging in my mind. Something envisioned in the domain of their tacit knowledge must be accepted in the domain of our tacit knowledge ...'. " (senior manager, quoted by Ichijo et. al. 1998: 184).

Just as, for example, the nurse entertained feelings about the patient's condition, or the shipyard workers felt they had a better plan than managers, so here managers claim to feel others' tacit knowledge; they have tacit knowledge (themselves) of others' tacit knowledge. Nonaka and Takeuchi's otherwise puzzling examples of customer interaction, and of the development of new products from analogies and metaphors produced by senior managers or team leaders (1995: 64-67) may well have involved similar processes.

\section{Trained expertise as tacit knowledge}

The phrase 'tacit knowledge' is also used to refer experts' knowledge and skills that "have become tacit through time" although they were acquired explicitly (Ambrosini \& Bowman 2001: 815). Patel et. al. (1999: 82) used 'tacit knowledge' to refer to the highly structured biomedical knowledge base of experts acquired through repeated exercise in different contexts that enables them to make immediate non-analytic responses to problems presented to them. While novices engage in relatively lengthy reasoning processes, experts' inference chains are shorter and difficult to 'unpack' because "the underlying knowledge has become tacit". They found similar characteristics in nurses (Patel et. al. 1999:87-8) whose decision making they described as 'pattern recognition'. Another study of medical practitioners (André et. al. 2002: 619) identified doctors' 'rules of thumb' of which those for medical conditions "were formulated as axiomatic simplified medical knowledge". As in the previous examples, this knowledge is tacit in use, but it was originally learned explicitly. Moreover, that explicit knowledge can be 'recovered' if for example the immediate non-analytical decisions appear not to work. Thus Patel et. al. (1999: 94-5) report that doctors' biomedical knowledge remains tacit during clinical decision making, unless problems arise.

Given this evidence some of the examples discussed earlier might also belong here. Collins' (2001a: 74-79; 2001b113) notion of 'tradition' suggests something that was once explicitly attended to, but which has become done by force of habit, as do his motor-skills examples (Collins 2001b:108-12), and conventional rules (many of which which are typically taught explicitly at some stage of a person's life - Collins 2001b: 110). Indeed, Janik (1988: 56) explicitly distinguished social conventions ("regulative rules") from "tacit knowledge in the strict sense" of knowledge that cannot be made explicit. Wagner and Sternberg (1986) argue that in a work context, knowledge of managing oneself, one's tasks, and others, are aspects of 'tacit knowledge' but in so far as people receive training in work-related activities, much of this may also be routinized formerly explicit practice. Similarly, Spender (1996: 60-61) tells us that experienced typists cannot replace the keys on a typewriter keyboard, drivers attend to 
several things at once, and a skilled musician focuses on interpreting the work, unaware of the mechanics of playing. But at one time the typists must have consciously learned where each key is; drivers will have had their attention drawn to important things to look out for; and musicians will have had to attend to the mechanics of playing.

\section{Innate and prior knowledge}

So far 'tacit knowledge' has been used to refer to some form of knowledge relevant to a practice that was acquired either through training for that practice, or experience in it. Others, however, use the phrase to refer to knowledge that unconsciously affects a practice, but which was acquired prior to and thus independently of it. In these cases, the source of 'tacit knowledge' is implicitly or explicitly attributed either to biology, or to culture, or to both.

Collins wrote that riding a bicycle is a paradigm of "tacit knowledge under the motor skills heading". Extending this to include other motor activities, such as dancing, he remarked that, "we can see much of what is tacit knowledge as far as humans are concerned is tacit only because of the way we are made" (Collins 2001b: 108-12). Thus again some of the examples in Table 1 might fit into this use category. Janik (1988: 57) argued that "constitutive rules", which, cannot be made explicit, are virtually indistinguishable from behaviour itself, and such "rule-following [has] a peculiar internal order which is determined by our natural history ...".

Torff (1999: 195) showed that trainee teachers begin their training with a "tacit and intuitive" notion of pedagogy arising from two sources - innate predispositions, and folk psychology, the ways we learn about teaching and learning through our culture. Collins (2001b: 110) also includes rules of behaviour as 'tacit knowledge' but he appears to focus on social conventions - thus rather than being innate, as the notion of regulatory rules suggests, they are simply prior to other activities in which they take effect because learned as the culture is learned. In similar vein, Janik (1988: 54-5) talked of every-day assumptions as 'tacit knowledge' and Spender (1996: 62) referred to the taken-for-granted knowledge people acquire during their upbringing. Baumard (1999: 119-138, 155-175) reports examples of a company merger where conflict between different groups' habitual ways of functioning were among the causes of post-merger difficulties. We might also include the ability to speak a language, which Collins describes as something people do "without knowing how they do it" (2001a: 72-3) in either the innate or the upbringing dimensions of this category, depending on which theory of the origin of language is adhered to.

\section{Things known to actors, but not to observers}

In the final set of examples 'tacit knowledge' is used where the actor (or one of a set of actors) clearly is aware of and able to articulate their knowledge. Horvath et. al. (1999) asked US army personnel to recall incidents from which they had learned something which they did apparently without any difficulty. Some had learned that it is important to delegate, and how this might be done; others had learned not to publicly contradict their superior officer. Similarly, Collins (2001a: 74-80) described how Russian scientists ran trial experiments at a different rate from the real experiments, because this allowed them to speed up the process (and learn about it) while sacrificing some accuracy. Presumably they did know at what rates the experimental runs were made at; they simply did not report such trials in their final publications.

Boiral (2002) describes a number of instances of 'tacit knowledge' it which it is evident that the actors were quite aware of and could, under the right conditions, describe what they knew. A foreman knew that the factory was exceeding permitted dust emission levels when he could no longer see the hands of a clock across the factory. Workers unloading butane were quite 
aware of leaks (but unaware of their significance until after safety training), while another knew all about a particular dust leak, and a retired worker knew where hazardous waste had been buried. Leonard and Sensiper's (1998) kiln operator, and Johannessen et. al.'s (2002) shipyard workers, mentioned above, might also fit with this group depending on whether their inability to explain was absolute, or whether simply they felt that talking, particularly to people unfamiliar with important artefacts, would not be fruitful. Calling this "ostensive knowledge" (Collins 2001a: 80) highlights the idea that such knowledge can be made explicit when relevant features can be indicated directly.

There is no suggestion in these examples that those 'possessing' the 'tacit knowledge' wanted or intended to withhold it from others. However, 'tacit knowledge' is also used in respect of the intentional withholding of knowledge by one person or group from another. Thus Janik (1988: 54-5) points out that 'tacit knowledge' has been used to refer to the maintenance of 'trade secrets'. and Collins (2001a: 72) refers to 'tricks of the trade' that professionals, craft workers and so on intentionally keep to themselves. This seems akin to the notion of 'knowledge as power'.

These examples all seem fit the following pattern: A and B are both, in some degree, involved in the same practice; A knows something but does not tell B, either because they feel unable to, or they wish to keep it a secret. We might also infer that A's not telling may only be because they have not been asked. It is striking that these things appear known explicitly to 'insiders' but not to 'outsiders' - managers are unaware of workers' knowledge about plant faults and dangerous emissions, or of details that would help them understand shipyard workers' plans. Army trainers and senior officers implicitly did not know what officers had learned through experience, (otherwise they would hardly have commissioned the research into tacit knowledge); and the kiln operator simply felt unable to explain to an outsider.

In so far as managers or senior officers, and subordinates, are both in the same practice, then these examples fall into the pattern indicated above - A (the subordinates) know something, but do not tell B (managers, superior officers). Moreover, now that it is known (at least through the studies undertaken by outsiders) it appears that B feels what A knew was important to B's role in the overall practice. The only actors to whom it might be claimed the knowledge was 'tacit' is thus the B's.

\section{Discussion}

It appears that 'tacit knowledge' has been used in at least six distinct ways as regards individuals (i.e. excluding questions of collective or organizational tacit knowledge) - see Table 2.

Table 2 : Uses of 'tacit knowledge' - summary

(a) someone can do something, but apparently cannot give an account

(b) someone claims they feel something of which they cannot give an account, but it is not clear if subsequent events validate the claim

(c) someone can do something, but not give an account at that moment, but can, if pressed, recall the explicit knowledge that was used tacitly when acting

(d) knowledge existing prior to the situation in which it is effective, and due to innate (biological) characteristics

(e) knowledge existing prior to the situation in which it is effective, and due to cultural factors

(f) situations where A knows something that B does not, but where it could be argued A and B share the same practice 
The use of 'tacit knowledge' to refer to situations where actors can tell (f), even if they feel they require contextual props clearly stands apart from the other use categories. This is not only because they can express their knowledge, but also because the way the alleged tacit knowledge has been identified departs from that characterizing the other five use categories. For some (e.g. Herbig et al 2001: 689) the very inability of someone to articulate their knowledge is evidence of tacit knowledge. Others argue that tacit knowledge has to be inferred from behaviour (Horvath et al 1999: 45; Patel et. al. 1999; Argyris 1999: 133-4; Ambrosini \& Bowman 2001: 816-9). Neither of these methods is applicable where A knows something that B does not, and can say, so there is no need to infer. B, on the other hand, has exhibited no behaviour with respect to the objects about which A is knowledgeable, and cannot say because they are totally unaware of the objects in question! In short, they are ignorant.

The use of tacit knowledge in situations where people claim to feel something (b) also poses some difficulties. (It is not a question of challenging their feelings, but of whether feelings amount to sufficient evidence comparable to that of accomplished behaviour such that the term 'tacit knowledge' can be applied consistently). Here, first the validating evidence of an accomplished action is usually absent, and second, it is often difficult to accept the implied link between the claim and the outcomes. The likely chain of events linking a nurse's claim to know something about a patient, and refutation or validation of that feeling, is quite short, and open to empirical investigation. Either their patient is subsequently found to need treatment (or dies), or not. In the latter case there would probably be no record since there is no interest in recording erroneous intuitions. If it could be shown that nurse intuition is right more often than it is wrong, then we would have convincing evidence of the validity of their claim. Moreover, there may be a material basis for nurses' intuition - breath contains volatile compounds that can be detected by people, and such aromas have been used as clues to diagnosis (Phillips 1992). It is possible, though it remains to be demonstrated, that nurses' intuitions involve detecting such aromas.

When we look at claims to have tacitly understood someone else's tacit knowledge (Ichijio et. al. 1998), then we seem to be on less firm ground. Unlike the nurses' claims to have felt something about a patient who was present, these appear to involve a retrospective claim to have felt something in the past that current events validated. Thus it only makes sense to claim to have understood customers' tacit needs in so far as current new products are selling well, or in so far as two managers happen to agree on policy and practice even though they did not formally plan such agreement. Not only is the chain of evidence that could link such tacit knowledge with the outcomes very tenuous, these cases seem to exemplify well-documented decision-making biases (Bazerman 1998) rather than some hidden knowledge about the future.

The remaining four ways in which 'tacit knowledge' has been used (a, c, d, and e) share the property that the knowers were unaware of critical knowledge, at the point of use. However, experts' knowledge was previously learned explicitly (as may also be the case with some cultural and even come motor- or mental-skills). What distinguishes examples involving experts from those of cultural or experiential knowledge is that the experts can also recall their explicit knowledge. Where cultural knowledge is concerned, some kind of technology (such as an ethnographer's report, or a self-completion questionnaire) seems needed to make that knowledge explicit.

The evidence for implicit learning and its effects (Stadler \& Frensch 1998; Lewicki et. al. 1997) shows that learning without awareness as a result of doing something is a real phenomenon. Many of the examples of people's ability to do (use group (a)) but not say 
probably exhibit symptoms of implicit learning and thus of knowledge that is both acquired and held tacitly. It is likely that much cultural knowledge (use e) is also acquired in the same way - indeed the main difference between (a) and (e) lies in the nature of the experiences: in the first instance we are concerned with the specific practices to which the tacit knowledge applies and through which it was engendered, while in the second, the tacit knowledge arises from other practices, and is brought into the specific practice.

There is a difficulty concerning situations where people can do, but not tell (a) that stems from the logic by which tacit knowledge is identified. We have noted that tacit knowledge is typically inferred by an observer. As a general procedure this is so natural that we seem unaware of the difficulties into which this might lead us despite the widespread evidence of errors of social judgement that occur all the time. In this context the main problem lies in that the inference cannot be validated independently of the evidence used to infer it. Two of Collins' studies (Collins 2001, a, b) illustrate the consequences.

In the sapphire measurement case, Collins argues that because the Russian scientists had successfully completed the experiment, things like the critical length of the thread, the materials of which it was made, and so on, were tacitly known to them. In the same vein, commenting on an earlier study (Collins 1974) where the length of an electrical lead turned out to be the critical factor, he says "the fact that the leads had to be short was 'known' by those who used the traditional design, but it was known tacitly." (Collins 2001b:113).

However, it is clear from his accounts that those who first carried out successful experiments subsequently discovered, in the course of trying to show others how they had done it, that they had been totally unaware of the significance of certain 'mindless' (Langer 2000) practices. In other words, the scientists were ignorant of what had been vital to their success, and unaware of that ignorance. True to the logic of inferring 'knowledge' from behaviour, Collins calls this tacit knowledge, but it seems to stretch the language too much to call ignorance 'knowledge' even if qualified as 'tacit'.

\section{Conclusions}

Clearly it is desirable to have a consistent use for a phrase to facilitate communication and to avoid condemning ourselves to a Sisyphean task. We have seen that the phrase tacit knowledge, even when limited to the individual level of analysis, has been used in at least six distinct ways. It seems sensible not to use the phrase where there is no question of the knower not being able to say, either because they are explicitly aware of something (its just that someone else is not), or where they can readily bring the explicit knowledge that underpins their behaviour to mind (experts). Some claims to feel something seem better treated as examples of perceptual or cognitive bias rather than evidence for any kind of knowledge. Some such claims, however, might well be due to implicit learning, as are many of the abilities acquired during the course of a practice. These, together with knowledge acquired in other practices (culture) or in some sense innate, seem to form a set of examples where the knower is not conscious of what they know, and cannot readily recall it to mind or express it in explicit forms.

Identification of such knowledge rests on an observers' inferences. In so far as a concept of knowledge that is tacit is useful, these three uses seem valid, although we might wish to emphasise the distinctions between them. From a practical perspective, for example, there are implicitly limits on the extent to which innately derived knowledge can be influenced. The difficulties of managing culture show some of the problems that might be involved there too. Once it is understood how experiences shape what is learned, then we might be in a better position to design work to enhance forms of tacit knowledge that are deemed useful and important. 
Turning to some of the ambiguities raised earlier in this paper, it seems likely that some differences are due to a focus on quite distinct empirical phenomena. The apparent conflict of opinion over whether tacit knowledge arises from direct experience, or is due to prior experiences, is reconciled if we recognize that people cannot but bring their past with them to current experiences, and that all three sources influence an individual's knowledge and skills. As regards the tacit knowledge and innovation, it is difficult to see how internalized routines can be regarded as a source of innovation, and on the contrary, easy to see how they can be a source of conservatism. On the other hand, if inquiries are made to discover just how something was achieved (as in Collins' studies, for example) then clearly novel understandings can be generated.

So far as making tacit knowledge explicit is concerned, it seems useful to distinguish the actual knowledge that allegedly underpinned someone's actions, and the rules that can be inferred by an observer. The latter may not have governed the actors (they may have been ignorant of certain aspects of their behaviour) but, in so far as they are complete, can form the basis for regulating that activity explicitly. Collins' case studies again exemplify this process, while MacKenzie and Spinardi (1996: 235) refer to the possibility of re-creating tacit knowledge by studying records (of explicit knowledge, and behaviours) and experimentation. In this way, nations other than the US developed nuclear weapons. Such possibilities can clearly be of value to organizations seeking to control the tacit knowledge of their employees since while there is no way of ever showing that the tacit knowledge of key workers has been captured, $a$ set of rules enabling reproduction of that tacit knowledge can be established. (This does not mean that these will not require further tacit knowledge to underpin them, but this may derive from innate or cultural sources as much as from specific task related practices).

\section{References}

Ambrosini, V. and Bowman, C. (2001) Tacit knowledge: Some suggestions for operationalization. Journal of Management Studies 38, 811-829.

André, M., Borgquist, L., Foldevi, M. and Mölstad, S. (2002) Asking for 'rules of thumb': a way to discover tacit knowledge in general practice. Family Practice 6, 617-622.

Argyris, C. (1999) Tacit knowledge and management. In: Sternberg, R.J. and Horvath, J.A., (Eds.) Tacit knowledge in professional practice, pp. 123-140. Mahwah, NJ and London: Lawrence Erlbaum Associates

Baumard, P. (1999) Tacit knowledge in organizations, edn. London \& Thousand Oaks: Sage.

Bazerman, M. (1998) Judgement in managerial decision making, 4th edn. New York, Chichester: John Wiley \& Sons.

Boiral, O. (2002) Tacit knowledge and environmental management. Long Range Planning 35, 291-317.

Choo, C.W. (1998) The knowing organization: how organizations use information to construct meaning, edn. New York, Oxford: Oxford University Press.

Colis, D. (1996) Organizational capability as a source of profit. In: Moingeon, B. and Edondson, A., (Eds.) Organizational learning and competitive advantage, pp. 139-163. London \& Thousand Oaks: Sage

Collins, H.M. (1974) The TEA set: tacit knowledge and scientific networks. Science Studies 4, 165-186. 
Collins, H.M. (2001a) Tacit knowledge, trust, and the Q of sapphire. Social studies of science 31, 71-85.

Collins, H.M. (2001b) What is tacit knowledge? In: Schatzki, T.R., Knorr Cetina, K. and von Savigny, E., (Eds.) The practice turn in contemporary theory, pp. 107-119. London and New York: Routledge

Cook, S.D.N. and Brown, J.S. (1999) Bridging epistemologies and the genreative dance between organizational knowledge and organizational knowing. Organization Science 10, 381-400.

Donaldson, L. (2001) Reflections on knowledge and knowledge-intensive firms. Human relations 54, 955-963.

Easterby-Smith, M. and Lyles, M.A. (2003) Introduction: watersheds of organizational learning and knowledge management. In: Easterby-Smith, M. and Lyles, M.A., (Eds.) The Blackwell Handbook of Organizational Learning and Knowledge Management, pp. 1-15. Malden, MA; Oxford: Blackwell Publishing Ltd

Fleck, J. (1996) Informal information flow and the nature of expertise in financial services. International Journal of Technology Management 11, 104-128.

Gourlay, S.N. (2004) Knowing as semiosis: steps towards a reconceptualization of 'tacit knowledge. In: Tsoukas, H. and Mylonopoulos, N., (Eds.) Organizations as Knowledge Systems, London: Palgrave Macmillan

Herbig, B. and Büssing, A. (2003) Comparison of therole of explicit and implicit knowledge in working. Psychology Science 45, 165-188.

Herbig, B., Büssing, A. and Ewert, T. (2001) The role of tacit knowledge in the work context of nursing. Journal of Advanced Nursing 34, 687-695.

Horvath, J.A., Forsythe, G.B., Bullis, R.C., Sweeny, P.J., Williams, W.M., McNally, J.A., Wattendorf, J.A. and Sternberg, R.J. (1999) Experience, knowledge, and military leadership. In: Sternberg, R.J. and Horvath, J.A., (Eds.) Tacit knowledge in professional practice, pp. 3958. Mahwah, NJ and London: Lawrence Erlbaum Associates

Ichijo, K., von Krogh, G. and Nonaka, I. (1998) Knowledge enablers. In: von Krogh, G., Roos, J. and Kleine, D., (Eds.) Knowing in firms. Understanding, managing and measuring knowledge, pp. 173-203. London: Sage

Janik, A. (1988) Tacit knowledge, working life and scientific method. In: Göranzon, B. and Josefson, I., (Eds.) Knowledge, skill and artificial intelligence, pp. 53-63. London \& Berlin: Springer-Verlag

Johannessen, J.-A., Olaisen, J. and Olsen, B. (2001) Mismanagement of tacit knowledge: the importance of tacit knowledge, the danger of information technology, and what to do about it. International Journal of Information Management 21, 3-20.

Josefson, I. (1988) The nurse as engineer - the theory of knowledge in research in the care sector. Göranzon, B. and Josefson, I., (Eds.) 19-30. London \& Berlin: Springer-Verlag.

Langer, E.J. (2000) The construct of mindfulness. Journal of Social Issues

Leonard, D. and Sensiper, S. (1998) The role of tacit knowledge in group innovation. California Management Review 40, 112-132.

Lewicki, P., Hill, T. and Czyzewska, M. (1997) Hidden covariation detection: a fundamental and ubiquitous phenomenon. Journal of Exprimental psychology-learning memory and cognition 23, 221-228. 
MacKenzie, D. and Spinardi, G. (1996) Tacit knowledge, weapons design and the uninvention of nuclear weapons. In: MacKenzie, D., (Ed.) Knowing machines Essays on Technical Change, pp. 215-260. Boston, MA: MIT Press

Nelson, R. and Winter, S. (1982) An evolutionary theory of economic change, edn. Cambridge, MA: Belknap Press.

Nonaka, I. (1991) The knowledge-creating company. Harvard Business Review 96-104.

Nonaka, I. and Takeuchi, H. (1995) The knowledge-creating company, edn. New York, Oxford: Oxford University Press.

Patel, V.L., Arocha, J.F. and Kaufman, D.R. (1999) Expertise and tacit knowledge in medicine. In: Sternberg, R.J. and Horvath, J.A., (Eds.) Tacit knowledge in professional practice, pp. 75-100. Mahwah, NJ and London: Lawrence Erlbaum Associates

Phillips, M. (1992) Breath tests in medicine. Scientific American 74-79.

Richardson, K. (1998) Models of cognitive development, edn. Hove: Psychology Press.

Scharmer, C.O. (2000) Organizing around not-yet-embodied knowledge. In: von Krogh, G., Nonaka, I. and Nichiguchi, T., (Eds.) Knowledge Creation. A source of value, pp. 13-60. Basingstoke and London: Macmillan Press

Spender, J.-C. (1996) Competitive advantage from tacit knowledge? Unpacking the concept and its strategic implication. In: Moingeon, B. and Edondson, A., (Eds.) Organizational learning and competitive advantage, pp. 56-73. London \& Thousand Oaks: Sage

Stadler, M.I. and Frensch, P.A. (1998) Handbook of implicit learning, London: Sage.

Torff, B. (1999) Tacit knowledge in teaching:: folk pedagogy and teacher education. In:

Sternberg, R.J. and Horvath, J.A., (Eds.) Tacit knowledge in professional practice, pp. 195214. Mahwah, NJ and London: Lawrence Erlbaum Associates

Tsoukas, H. (2003) Do we really understand tacit knowledge? In: Easterby-Smith, M. and Lyles, M.A., (Eds.) The Blackwell Handbook of Organizational Learning and Knowledge Management, pp. 410-427. Malden, MA; Oxford: Blackwell Publishing Ltd

Wagner, R.K. and Sternberg, R.J. (1985) Practical intelligence in real-world pursuits: the role of tacit knowledge. Journal of Personality and Social Psychology 49, 436-458.

Wagner, R.K. and Sternberg, R.J. (1986) Tacit knowledge and intelligence in the everyday world. Sternberg, R.J. and Wagner, R.K., (Eds.) 51-83. Cambridge: Cambridge University Press.

Wagner, R.K. and Sternberg, R.J. (1991) Tacit knowledge inventory for managers, edn. San Antonio: The Psychological Corporation.

Willman, P., Fenton O'Creevy, M.P., Nicholson, N. and Soane, E. (2001) Knowing the risks: theory and practice in financial markets trading. Human Relations 54, 887-910. 